Review Article

\title{
A General Look at Pharmacogenetic and Its Future
}

\author{
Onur Ozturk ${ }^{1, ~ *}$, Izzet Fidanci ${ }^{2}$ \\ ${ }^{1}$ Asarcik Family Health Center, Samsun, Turkey \\ ${ }^{2}$ Atakum Community Health Center, Samsun, Turkey
}

Email address:

dr.onurozturk@yahoo.com (O. Ozturk)

\section{To cite this article:}

Onur Ozturk, Izzet Fidanci. A General Look at Pharmacogenetic and Its Future. Journal of Family Medicine and Health Care. Vol. 1, No. 3, 2015, pp. 33-35. doi: 10.11648/j.jfmhc.20150103.11

\begin{abstract}
Considering any disease, it is known that there are differences in response to the standart dose of medical treatment among individuals. This causes problems such as treatment nonresponsiveness or observation of side effects in clinic applications. It is known that many factors such as age, weight, gender, disease itself or drug interactions may effect the response to the drug used. As pharmacogenetic provides patient-specific treatment, it brings innovations in the treatment of all diseases, mainly cancer and psychiatric diseases. In our compilation, we will cover the developments and innovations in this field of science.
\end{abstract}

Keywords: Pharmacogenetic, Individual Treatment, Gene

\section{Introduction}

Pharmacogenetic examines the contribution of genetic factors in the formation of the differences observed among individuals or different societies in the responsiveness to drug or development of toxicity. Genetic factors demonstrate their effect with the changes in the genes encoding enzymes or proteins which play a part in the pharmacokinetic or pharmacodynamic of the drug. These enzymes which protect the organism by turning the chemical materials into new molecules differ between individuals. So different individuals turn the same drug into new molecules in different amounts. Also the metabolites of many drugs are active, not themselves. While these drugs are designed, it is assumed that the enzymes of the patients which activate the drug share the same characteristics. So individual differences are not considered.

Genetic factors are responsible for $20-40 \%$ of the individual differences in the responses to the drug and $50 \%$ of the side effects. Malign hyperthermia, Suxamethonium sensitivity, Acetylation polymorphism, glucose 6-phosphate dehdrogenase deficiency (G6PD) are examples of some pharmacogenetic diseases.

If individual differences in genes fulfilling the same function are seen in less than $1 \%$ of the society, they are called mutation and if they are seen in more than $1 \%$, they are called polymorphism. Polymorphisms in the genes synthesizing the proteins with which drugs interact may cause changes among individuals in the response to drugs. Determination of these polymorphisms before the treatment, applying a genetic test may provide individual drug use but the use of these tests in clinic is limited today due to the few number of prospective studies. [1-6]

Today, pharmacogenetic science classifies a group of enzymes belonging to "Cytohrome P450 (CYP) enzyme system working in the metabolism of most of the drugs and materials taken from the outside and their elimination from the body are classified according to the structural differences in the genes which form them. According to the "Genomic Profile" created by mostly the genes belonging to CYP enzymes, with information such as the individual responses to more than 300 drugs; the interaction of these drugs with each other, interaction of tea, coffee, cigarette and alcohol with each other and with the drugs, individual and safe treatment is made.

Many drugs frequently used in neurological and psychiatric disorders are also metabolized and decomposed by Cytochrome P450 enzyme group in the same way. Since the activity of this enzyme group changes in every individual, while the same drug dose given reaches the satisfactory treatment dose in some individuals, it won't be effective in some patients and will have a toxic effect for some others. [7]

Pharmacogenetic studies have a distinct importance in cases where pharmacotheraphy is unsatisfactory/expensive, 
in psychiatric diseases and polygenic complex diseases such as cancer.

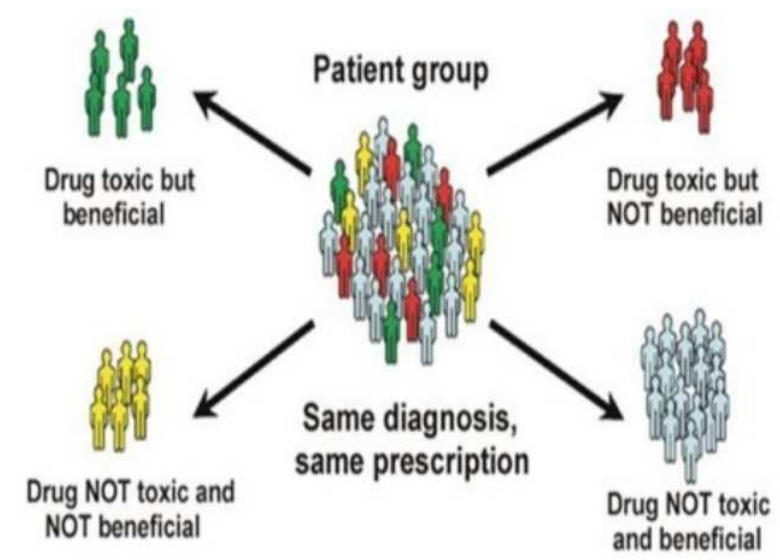

Figure 1. Different patients, different results [8].

Pharmacogenetic testing is available to guide prescription drug treatment decisions, such as which drug or dose to use for specific patients based on their genotype. It's information can also affect patient safety and drug-related hypersensitivity reactions. In a psychiatric study, Brennan FX et al. reported that the patient data demonstrated statistically significant decreases in depression and anxiety symptoms and medication side effects and a significant increase in quality of life by the pharmacogenetic testing. [9]

Testing is increasingly becoming the new standard of care for a variety of drugs used to treat different disease states. As the result of pharmacogenetic tests, the treatment chosen doesn't cause the patient to lose time and prevents the disease from becoming chronic.

The costs of Pharmacogenetc tests to be made are rather cheap when factors such as reapplication of a patient who had an unsuccessful treatment to another doctor, costs of prescription caused by the treatment changed everytime, hospitalizations, other medical tests to be done, side effects which may occur and the treatments of these and workforce loss are considered. Giving $5 \mathrm{ml}$ blood or cheek swab would be enough for the pharmacogenetic test. Dose adjustment can be made in patients in whom it can be determined in advance that the drug concentrations may reach toxic level in plasma or tissues. So Curative Medicine Blood Level Monitorization and genetic profile determination tests are made as laboratory tests. Techniques determining the drug-blood level among pharmacological laboratory tests have advanced a great deal in the recent years. Clinician changing "blind use" application when prescribing a drug to the patient is the most important target desired. [5]

\section{Discussion}

\subsection{Pharmacogenetic and Pharmacology}

Defining the changes in genetic structures is very important for the application of required strategies and development of treatment providing methods. In the studies made, presence of genetic areas providing the regulation of enzymes effective in eliminating the drugs used for treatment from the body was presented. Also it was proved that genetic changes have an active role in determination of the drugs to be used for cancer treatment. Cancer pharmacogenetic is based on the difference in drug response due to the variants in the hereditary or somatic DNA of the individual. But molecular classification of the disease is also required for effective drug treatment. [7] Today drug sensitivities and effective treatments in cancer patients may be determined in advance with the genetic tests applied.

Drug sensitivities can be determined in advance with the genetic tests made using warfarin, klopidogrel and antipsychotic drugs often preferred for treatment. Patients can be protected from the undesired side effects by making dose adjustments for drugs determined to cause toxicity or preferring alternative drugs.

When pharmacokinetic studies are made on the drugs, we mostly work on those which metabolize the drug in normal ranges. The genes in these individuals which encode the enzymes decomposing the drugs are present in most of the society. In these individuals, standard doses provide the drug blood levels which may be satisfactory for treatment. [10]

\subsection{Pharmacogenetic and Economy}

All countries should also evaluate pharmacoeconomy when determining economical applications in health which are inevitable. Pharmacoeconomy prevents wasted consumption. This would be possible with medical application for individual based on pharmacogenetic information. [11]

Assessing the clinical and economic value of pharmacogenetic testing for reimbursement has been described as challenging because research methods applied to traditional medicines have to adapt in order to evaluate the scope and complexity of personalized medicine. Yet the requirement of clinical evidence and value is beginning to favor reimbursement for testing. [12-14]

Up to now, around 140 drugs (for example: Omeprazole, Risperidone, Warfarin) approved by the United States Food and Drug Administration (FDA) include pharmacogenetic-related information by their labels. [15] Based on drug utilization data from a single large pharmacy benefits manager, Frueh et al estimated that almost a quarter of patients in 2006 (approximately 8.8 million) were prescribed drugs for which pharmacogenetic information was included in the drug labels. [16] Almost a decade later, it we would be anticipated this number to have increased radically. [17]

\begin{tabular}{lcl}
\hline \multicolumn{1}{c}{ Polymorphism } & Daily Warfarin Dose & \multicolumn{1}{c}{ Resistance Phenotype } \\
\hline & $m g$ & \\
Wild type & $4-6$ & \\
A41S & 16 & Moderate \\
R58G & 34 & Major \\
V66M & 31 & Major \\
L28R & $>45$ & Severe \\
V45A & Target INR never & Severe \\
& reached & Variations across the \\
Common SNPs in & $1-15$ & "normal" dosing range \\
noncoding regions & &
\end{tabular}

Figure 2. VKORC1 polymorphisms and warfarin resistance. 
Haga et al's finding of lack of inclusion and consistency regarding the type of pharmacogenetic information in patient sections of drug labels suggests that not all patients are made aware of pharmacogenetic information that may be useful in understanding the possible risks and benefits of taking their medication. [17]

\section{Results and Recommendations}

Although studies made in pharmacogenetic field increase recently, the reasons for the delay to pass to the widespread clinic application are incoherent/conflicting results reported. With recent developments in pharmacogenetic field and research method and technology and wider clinical studies to be made in this field, individualization of treatments would be possible. Pharmacogenetic applications becoming widespread provides more effective use of country economy in addition to individual interest. [18]

Collaborating with the pharmacogenomic laboratories working on individual medicine, the doctors may present a more effective treatment to their patients and prevent poisoning and deaths occuring due to drug dosage mistakes.

\section{References}

[1] Karabulut HG. Farmakogenetik: Laboratuvardan Klinik Uygulamaya. Turkiye Klinikleri J Med Sci 2010; 30(Suppl 1): S5-S15.

[2] Eichelbaum $M$, Ingelman-Sundberg $M$, Evans WE. Pharmacogenomics and individualized drug therapy. Annu Rev Med 2006; 57: 119-37.

[3] Percin EF. Hastalık ve Gen tedavisi- Farmakogenetik. Meslek ici surekli egitim dergisi. 2007; 19-20: 16-25.

[4] Lanfear DE, McLeod HL. Pharmacogenetics: using DNA to optimize drug therapy. Am Fam Physician 2007; 76(8): 1179-82.

[5] Benlier N. Bireye Ozgu Tedavi, Farmakogenetik. Bilim ve Bilim Adami 2014 http://bilimvebilimadami.com/bireye-ozgu-tedavi-farmakogen etik. (Accessed Nov 06, 2015).

[6] Weinshilboum RM, Wang L. Pharmacogenetics and pharmacogenomics: development, science, and translation. Annu Rev Genomics Hum Genet 2006; 7: 223-45.
[7] Ilgin Ruhi H. Meme Kanserinde Farmakogenetik. Turkiye Klinikleri J Med Sci 2010; 30 (Suppl 1): S16-S21.

[8] http://www.slideshare.net/TasneemHamadaHefney/pharmacog enetics-27975067?related=1 (Accessed Nov 13, 2015).

[9] Brennan FX, Gardner KR, Lombard J et al. A Naturalistic Study of the Effectiveness of Pharmacogenetic Testing to Guide Treatment in Psychiatric Patients with Mood and Anxiety Disorders. Prim Care Companion CNS Disord. 2015 Apr 16; 17(2).

[10] Saglam E. Farmakogenetik Testlerde Farmakologlar Nerede Durmalidir? TFD-KFÇG Elektronik Bulteni 2008; 08: 1-3.

[11] Laleli Y, Laleli Sahin E. Farmakogenetik ve Farmakoekonomi. Turkiye Klinikleri J Med Sci 2010; 30 (Suppl 1): S37-S46.

[12] D. Brixner, E. Biltaji, A. Bress et al. The effect of pharmacogenetic profiling with a clinical decision support tool on healthcare resource utilization and estimated costs in the elderly exposed to polypharmacy. J Med Econ. 2015 Oct 19: $1-40$.

[13] Faulkner E, Annemans L, Garrison L, et al. Challenges in the development and reimbursement of personalized medicine-payer and manufacturer perspectives and implications for health economics and outcomes research: a report of the ISPOR personalized medicine special interest group. Value Health. 2012; 15(8): 1162-1171.

[14] Meckley LM, Neumann PJ. Personalized medicine: factors influencing reimbursement. Health Policy. 2010; 94(2): 91-100.

[15] US Food and Drug Administration. Table of Pharmacogenomic Biomarkers in Drug Labels. Available from: http://www.fda.gov/Drugs/ScienceResearch/ResearchAreas/P harmacogenetics/ucm083378.htm. (Accessed Nov 10, 2015).

[16] Frueh FW, Amur S, Mummaneni P, et al. Pharmacogenomic biomarker information in drug labels approved by the United States Food and Drug Administration: prevalence of related drug use. Pharmacotherapy. 2008; 28(8): 992-998.

[17] Haga SB, Mills R, Moaddeb J. Pharmacogenetic information for patients on drug labels. Pharmgenomics Pers Med. 2014 Oct 3; 7: 297-305.

[18] Demirkazik A, Tukun FA. Kanserde Bireysellestirilmis Tedavi: Neden Farmakogenetik? Turkiye Klinikleri J Med Sci 2010; 30 (Suppl 1): S1-S4. 